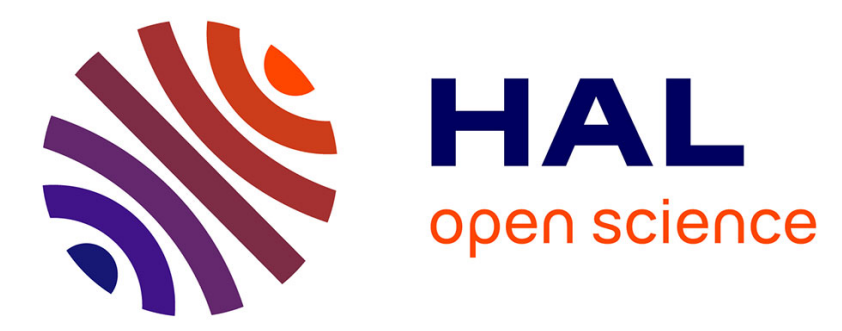

\title{
THE EFFECTS OF ADDITION OF Nb, Mo AND Ga ON THE MAGNETIC PROPERTIES OF Nd-Fe-B ALLOYS
}

Jifan Hu, Yizhong Wang, Xinwen Li, Lin Yin, Minying Feng, Daoyang Dai, Tao Wang, J. Zhao, Zhenxi Wang

\section{To cite this version:}

Jifan Hu, Yizhong Wang, Xinwen Li, Lin Yin, Minying Feng, et al.. THE EFFECTS OF ADDITION OF Nb, Mo AND Ga ON THE MAGNETIC PROPERTIES OF Nd-Fe-B ALLOYS. Journal de Physique Colloques, 1988, 49 (C8), pp.C8-601-C8-602. 10.1051/jphyscol:19888274 . jpa-00228444

\section{HAL Id: jpa-00228444 https://hal.science/jpa-00228444}

Submitted on 1 Jan 1988

HAL is a multi-disciplinary open access archive for the deposit and dissemination of scientific research documents, whether they are published or not. The documents may come from teaching and research institutions in France or abroad, or from public or private research centers.
L'archive ouverte pluridisciplinaire HAL, est destinée au dépôt et à la diffusion de documents scientifiques de niveau recherche, publiés ou non, émanant des établissements d'enseignement et de recherche français ou étrangers, des laboratoires publics ou privés. 


\title{
THE EFFECTS OF ADDITION OF Nb, Mo AND Ga ON THE MAGNETIC PROPERTIES OF Nd-Fe-B ALLOYS
}

\author{
Jifan Hu, Yizhong Wang, Xinwen Li, Lin Yin, Minying Feng, Daoyang Dai, Tao Wang, J. G. Zhao \\ and Zhenxi Wang
}

Institute of Physics, Academy of Sciences, Beijing 100080, China

\begin{abstract}
The composition dependence of Curie temperature, spin reorientation temperature and magnetic anisotropy field are investigated for $\mathrm{Nd}_{2}\left(\mathrm{Fe}_{1-x} \mathrm{~T}_{x}\right)_{14} \mathrm{~B}(\mathrm{~T}=\mathrm{Nb}$, Mo and $\mathrm{Ga}$ ) alloys. The contribution of pinning to the magnetic hardening for NdFeNbB sintered magnets increases with the Nb addition. Precipitation has been found in NdFeNbB sintered magnet.
\end{abstract}

\section{Introduction}

$\mathrm{Nd}-\mathrm{Fe}-\mathrm{B}$ magnets have exceptionally high energy product. However, their thermal stability worse. Recent studies indicate that the addition of $\mathrm{Nb}[1], \mathrm{Mo}$ [2] and $\mathrm{Ga}$ [3] in $\mathrm{NdDyFeCoB}$ or $\mathrm{NdFeCoB}$ magnets not only enhance the coercivity but also improve the thermal stability. In this work, the intrinsic magnetic properties of $\mathrm{Nd}_{2}\left(\mathrm{Fe}_{1-x} \mathrm{~T}_{x}\right)_{14} \mathrm{~B}(\mathrm{~T}=\mathrm{Nb}, \mathrm{Mo}, \mathrm{Ga})$ and the permanent magnetic behavior of $\mathrm{NdFeNbB}$ sintered magnets are investigated.

\section{Experiment}

The samples were prepared by arc-melting of $99.5 \%$ pure primary materials followed by vacuum annealing at a temperature of $900{ }^{\circ} \mathrm{C}$ for 100 hours. The single phase was identified from X-ray diffraction spectra and thermomagnetic data. The Curie temperatures were determined by Hopkinson's method. The magnetic anisotropy field were measured using SPD method at room temperature. The spin reorientation temperatures were determined by an extracting sample magnetometer. The magnets with compositions $\mathrm{Nd}_{16} \mathrm{Fe}_{77-x} \mathrm{Nb}_{x} \mathrm{~B}_{7}$ were prepared by the conventional powder metallurgy method. The permanent magnetic properties were measured with a DC hysteresisgraph. Microstructural characterisation was obtained by SEM (scanning electron microscopy) and SEM X-ray microanalysis.

\section{Result and discussion}

The compositional dependence of the Curie temperature $T_{c}$, the spin reorientation temperature $T_{\mathbf{s r}}$ and the anisotropy field $H_{\mathrm{a}}$ for $\mathrm{Nd}_{2}\left(\mathrm{Fe}_{1-x} \mathrm{~T}_{x}\right)_{14} \mathrm{~B}$ $(\mathrm{T}=\mathrm{Nb}, \mathrm{Mo}$ and $\mathrm{Ga}$ ) are shown in figure 1. The Curie temperature decreases with the addition of Mo faster than with the addition of Nb. Superficially, one would expect that the replacement of a magnetic element such as $\mathrm{Fe}$ by a non-magnetic element would cause a reduction in $T_{\mathrm{c}}$. Surprisingly, a rise in $T_{\mathrm{c}}$ with $\mathrm{Ga}$

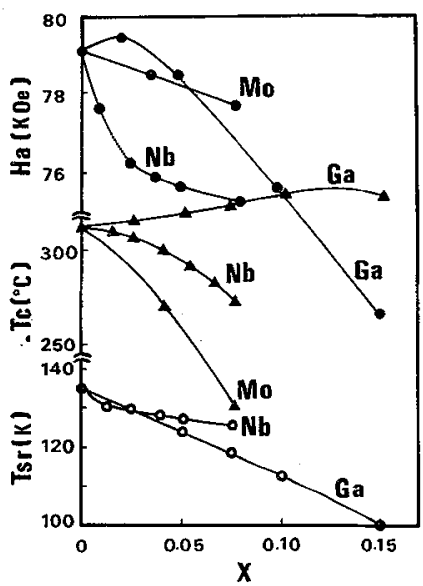

Fig. 1. - The composition dependence of Curie temperatures $T_{\mathrm{c}}$ spin reorientation temperatures $T_{\mathrm{sr}}$ and anisotropy field $H_{\mathrm{a}}$ for $\mathrm{Nd}_{2}\left(\mathrm{Fe}_{1-x} \mathrm{~T}_{x}\right)_{14} \mathrm{~B}, \mathrm{~T}=\mathrm{Nb}, \mathrm{Mo}$ and $\mathrm{Ga}$ alloys.

substitution in $\mathrm{Nd}_{2}\left(\mathrm{Fe}_{1-x} \mathrm{Ga}_{x}\right)_{14} \mathrm{~B}$ is observed. We know that the nearest neighbour distances between iron atoms, $d(\mathrm{Fe}-\mathrm{Fe})$, cover a range of values in $\mathrm{Nd}_{2} \mathrm{Fe}_{14} \mathrm{~B}$. For $d(\mathrm{Fe}-\mathrm{Fe})<2.50 \AA$, the magnetic interactions between iron are negative, while for iron located at larger distances these are positive [4]. Thus, the different effects on $T_{\mathrm{c}}$ by $\mathrm{Nb}$, Mo and $\mathrm{Ga}$ substitution is probably due to the different preferency to six $\mathrm{Fe}$ sites in $\mathrm{Nd}_{2} \mathrm{Fe}_{14} \mathrm{~B}$ tetragonal structure, and the increase of $T_{\mathrm{c}}$ in $\mathrm{Nd}_{2}\left(\mathrm{Fe}_{1-x} \mathrm{Ga}_{x}\right)_{14} \mathrm{~B}$ may be attributed to a higher contribution due to a decrease of negative exchange interaction. The spin reorientation temperatures decrease monotonically with rising $\mathrm{Nb}$ and $\mathrm{Ga}$ content in $\mathrm{Nd}_{2} \mathrm{Fe}_{14} \mathrm{~B}$. This results from effects of the high-order terms in CEF Hamiltonian [5]. The anisotropy field decreases with Mo much less than with $\mathrm{Nb}$. But the replacement of $\mathrm{Fe}$ by $\mathrm{Ga}$ leads to a rise in anisotropy field $H_{\mathrm{a}}$ for low $\mathrm{Ga}$ content. $H_{\mathrm{a}}$ decreases then with increasing $x$. The peak appears at $x=0.025$.

The niobium concentration dependence of perma- 


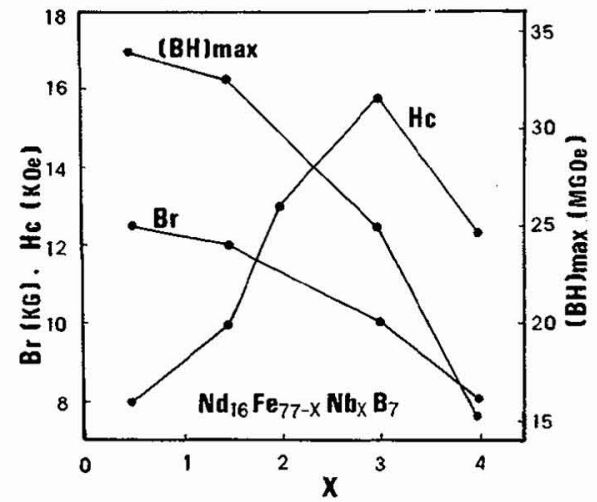

Fig. 2. - The niobium concentration dependence of permanent magnetic properties for $\mathrm{Nd}_{16} \mathrm{Fe}_{77-x} \mathrm{Nb}_{x} \mathrm{~B}_{7}$ sintered magnets.

nent magnetic properties, $B_{\mathrm{r}},{ }_{i} H_{\mathrm{c}}$ and $(B H)_{\max }$, is shown in figure 2 for $\mathrm{Nd}_{16} \mathrm{Fe}_{77-x} \mathrm{Nb}_{x} \mathrm{~B}_{7}$ sintered magnets. The remanence $\mathrm{Br}$ and the maximum magnetic product $(B H)_{\max }$ decreases with increasing niobium content. The intrinsic coercivity $H_{c}$ increases first, and then decreases with increasing niobium content. Comparing the composition dependence of the coercivity with that of the anisotropy, it is clear that the coercivity depends on not only the anisotropy but also the microstructure for $\mathrm{NdFeB}$ magnets.

The initial magnetizing field dependence of the coercivity for NdFeNbB sintered magnets in the thermally demagnetized state is shown in figure 3. The slope at the steps of the curves increases with increasing $\mathrm{Nb}$ content. This result indicates that contribution of pin-

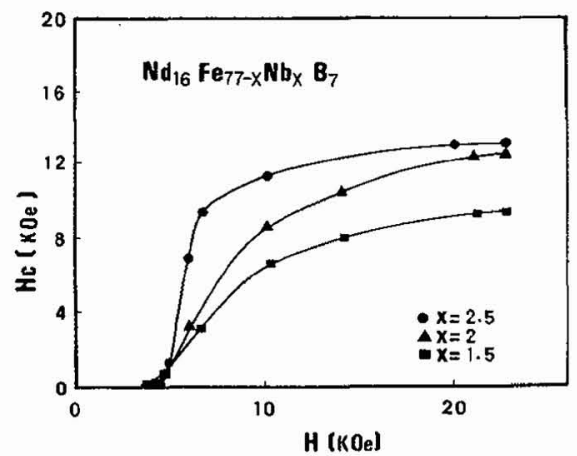

Fig. 3. - The initial magnetizing field dependence of the coercivity for $\mathrm{Nd}_{16} \mathrm{Fe}_{77-x} \mathrm{Nb}_{x} \mathrm{~B}_{7}$ sintered and thermaldemagnetized magnets. ning to the magnetic hardening increases indeed with low $(x \leq 3) \mathrm{Nb}$ content.

Microstructural characterisation was obtained by SEM and SEM X-ray microanalysis. There are four phases in the niobium-containing magnet. Besides the well known $\mathrm{Nd}_{2} \mathrm{Fe}_{14} \mathrm{~B}$-type phase, the tetragonal $\mathrm{NdFe}_{4} \mathrm{~B}_{4}$ and the Nd-rich phase, there also is a new phase precipitated. The figure 4 shows the electron micrograph of the $\mathrm{Nd}_{16} \mathrm{Fe}_{77-x} \mathrm{Nb}_{x} \mathrm{~B}_{7}(x=3)$ magnet. This precipitation occurs within the main phase and at grain boundaries (marked by arrows in Fig. 4). With energy dispersive $X$-ray spectra we determined the composition of this precipitation: $\mathrm{Nd}: \mathrm{Fe}: \mathrm{Nb}=7: 48: 45$, which can play the role of the pinning site.

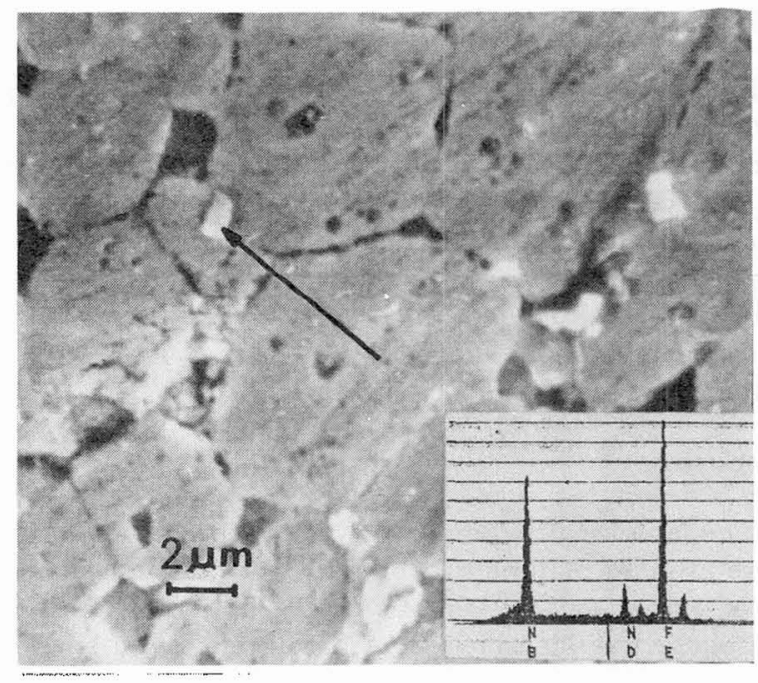

Fig. 4. - SEM micrograph and $\mathrm{X}$-ray microanalysis of a $\mathrm{Nb}_{16} \mathrm{Fe}_{77-x} \mathrm{Nb}_{x} \mathrm{~B}_{7} x=3$ sintered magnet.

[1] Tokunaga, M., Harada, H. and Trout, S. R., IEEE Trans. Mag-23 (1987) 2284.

[2] Shen, X. F., Wang, Y. Q., Diao, Z. T. and Liu, X. F., J. Appl. Phys. 61 (1987) 3433.

[3] Endoh, M., Tokunaga, M. and Harada, H., IEEE Trans. Mag-23 (1987) 2290.

[4] Givord, D., Li, H. S., Perrier de la Bâthie, R., Solid State Commun. 51 (1984) 857.

[5] Hirosawa, S., Matsuura, Y., Yamamoto, H., Fujimura, S. and Sagawa, M., J. Appl. Phys. 59 (1986) 873. 